\title{
The Construction of Chengdu New Economic Index and the Measurement of Industrial Development
}

\author{
Lijun Ran ${ }^{1, a}$, Jinyang Liu ${ }^{1, b}$ and Sheng Zhu' ${ }^{1, c, *}$ \\ ${ }^{1}$ School of Statistics, Chengdu University of Information Technology, Chengdu, Sichuan Province, \\ China \\ aran_ljun@126.com, ${ }^{b}$ lista@cuit.edu.cn, ctjx@cuit.edu.cn \\ ${ }^{*}$ Corresponding author
}

Keywords: New economic index, Industrial development, New normal economy.

\begin{abstract}
Chengdu has already led inland cities in developing new economic industries and has become a highland for the development of new economic industries. This paper establishes an index system that comprehensively reflects the development of Chengdu's new economy. It uses the Cobb-Douglas production function to synthesize the Chengdu New Economic Index. On this basis, it quantitatively measures the development of Chengdu's new economic industry. The study believes that the development level of Chengdu's new economic industry is in a relatively leading position in the country, but it still has a certain gap with coastal developed areas such as Beijing, Shanghai, Guangzhou and Shenzhen.
\end{abstract}

\section{Introduction}

In the 2016 "Government Work Report", China first proposed to accelerate the development of the new economy, marking the official rise of the development of the new economy as a major strategic deployment at the national level. At present, China is entering a critical period of the transition between old and new kinetic energy and a period of deepening the structural reform of the supply side. The new round of scientific and technological revolution and industrial transformation are accelerating the gestation period in the world. At this time, the formulation and implementation of the new economic strategy is significant and far-reaching. Accelerating the development of the new economy is not only the fundamental way to realize the transformation of the kinetic energy of the old and new developments, but also the inevitable choice to correctly lead the "new normal of economic development" and the important guarantee for "building a well-off society in an all-round way".

Chengdu has already led inland cities in developing new economic industries and has become a highland for the development of new economic industries. In October 2017, Chengdu's new economic aggregate index ranked fourth among cities nationwide, second only to Beijing, Shanghai and Guangzhou. According to its own resource endowment advantages and industrial development basis, Chengdu has put forward the "567" new economic industrial development path, that is, adhere to the new technology as the driving force, adhere to the new organization as the main body, adhere to the new industry as the support, adhere to the new industry as the engine, adhere to the new mode as the breakthrough of the "five new paths"; focus on the development of the "six new economic forms" of the digital economy, intelligent economy, green economy, creative economy, flow economy, and shared economy; Smart city construction, technology innovation and entrepreneurship, human capital coordination, consumption upgrade, green low-carbon development and modern supply chain innovation and application, build the "seven application scenarios" of the new economic industry.

In addition, Chengdu has certain comparative advantages in terms of living environment and labor costs compared with developed coastal areas. On this basis, Chengdu is committed to building a nation-leading new economic and industrial development environment. In December 2017, Chengdu issued the "Opinions on Creating New Energy for the Development of New Ecology and New Economy ", and put forward 18 items, such as creating a business environment and social atmosphere conducive to the development of new economy, creating a growth environment conducive to the 
development of new economic enterprises, and constructing an ecological and supply system conducive to the development of new economy. On the basis of traditional comparative advantages, the comprehensive environmental advantages of Chengdu's development of new economic industries are accelerating.

\section{The connotation and extension of the new economy}

There is a lot of controversy about the meaning of the "new economy." Some scholars believe that the key to scientifically interpreting the "new economy" is to grasp that the US economy is transforming from a traditional economy to a new economy - a knowledge economy. Some scholars believe that the so-called "new economy" refers to a new type of economy that is different from the previous traditional industries as the pillar industries and based on natural resources. This new type of economy is dominated by high-tech industries and relies on intellectual resources[1]. Some scholars believe that the meaning of the "new economy" in the United States needs to be further explored[2]. First, since the new economy is formed by economic globalization and information technology revolution, is this a unique economic phenomenon in the United States at this stage, or is it an international economic phenomenon that developed countries will gradually form? Secondly, is the "new economy" in the United States a phenomenon that exists in a period of time, or is it a phenomenon that has existed for a long time?

In March 2016, Premier Li Keqiang answered questions from reporters after the closing of the Fourth Session of the 12th National People's Congress. He pointed out that the coverage and connotation of the new economy is very broad, involving three major industries, not only referring to the Internet + products in the three industries. Emerging industries and formats such as networking, cloud computing, and e-commerce, including smart manufacturing and mass customization in industrial manufacturing, as well as family farms, shareholding cooperatives, and rural areas that are conducive to promoting moderate scale operations in the primary industry. Three industries integrated development and so on. Some studies have interpreted the "new economy" around the 2016 government work report.

The core of the new economy is the new economic industry, and the new economic industry is the main form of the new economy. At present, there is no definition of relevant new economic industries at home and abroad. Therefore, according to the characteristics of the new economy, this paper defines the new economic industry as: in the context of the new economic normal, the collection of new industrial forms such as artificial intelligence, 3D printing cloud computing based on new technologies, and the integration with traditional industries. Such as e-commerce, etc., the new model, new format. The characteristics of the new economic industry are: network, popularization, intelligence, individualization, unbounded and green. Its main representative industries include new energy auto industry, new materials industry, high-end equipment manufacturing, new generation information technology and information service industry, biomedical industry, scientific research and technology service industry, financial and legal service industry.

\section{Construction of new economic index}

\subsection{Establishment of indicator system}

The new economy is relative to the traditional economy. This paper mainly defines the new economy through three criteria: first, high human capital investment, high-tech investment, and light assets; second, sustainable and rapid growth; and third, it is in line with the direction of industrial development[3]. According to these three standards, this paper selects 144 sub-sectors, including a new generation of information technology and information service industry, energy conservation and environmental protection industry, high-end equipment manufacturing industry, bio-pharmaceutical industry, new energy industry, new material industry, new energy automobile industry. , high-tech 
services and research and development, financial services and legal services, sports culture and entertainment industry 10 industries.

Traditional industries mainly focus on low-end labor based on cost advantage in factor input, while new economic industries pay more attention to human capital and science and technology input in factor input. Therefore, there are significant differences between new and old industries in factor input. Referring to the New Economic Index of American States, the Silicon Valley Index and the Double Creative Index, and combining with the actual situation of Chengdu and the availability of industry data, this paper establishes the new economic evaluation index system of Chengdu as shown in Table 1. The system mainly includes three first-level indicators of labor input, capital investment, and scientific and technological innovation, nine indicators of new economic industry personnel salaries, new economic industry jobs, and new economic industry new patents.

Table 1. Circular economy comprehensive evaluation index system

\begin{tabular}{|c|c|c|}
\hline Primary indicator & Secondary indicators & Indicator description \\
\hline \multirow[b]{2}{*}{ Labor input } & $\begin{array}{l}\text { New economic industry personnel } \\
\text { compensation ratio }\end{array}$ & $\begin{array}{l}\text { Recruitment salary of new economic industry enterprises } \\
\text { accounted for the proportion of salary of all enterprises } \\
\text { during the period }\end{array}$ \\
\hline & New economic industry jobs & $\begin{array}{l}\text { The ratio of the number of recruitment needs of } \\
\text { enterprises in the new economic industry to the total } \\
\text { demand for recruitment in various industries during the } \\
\text { period }\end{array}$ \\
\hline \multirow{4}{*}{$\begin{array}{c}\text { Capital } \\
\text { investment }\end{array}$} & $\begin{array}{l}\text { The proportion of venture capital in } \\
\text { the new economy }\end{array}$ & $\begin{array}{l}\text { The total amount of venture capital invested by } \\
\text { enterprises in the new economic industry has been } \\
\text { disclosed as a percentage of total venture capital } \\
\text { investment by all enterprises. }\end{array}$ \\
\hline & $\begin{array}{l}\text { Proportion of tenders in the new } \\
\text { economic sector }\end{array}$ & $\begin{array}{l}\text { The number of bidding for new economic industry } \\
\text { projects in the main bidding website accounts for the } \\
\text { proportion of bidding for all industry projects }\end{array}$ \\
\hline & $\begin{array}{l}\text { Application for the proportion of } \\
\text { registered capital of new three board } \\
\text { new economic enterprises }\end{array}$ & $\begin{array}{l}\text { The total registered capital of new three-board new } \\
\text { economic enterprises in the period accounted for the } \\
\text { proportion of registered capital of all enterprises }\end{array}$ \\
\hline & $\begin{array}{l}\text { The proportion of registered capital } \\
\text { of newly added companies in the } \\
\text { new economic industry }\end{array}$ & $\begin{array}{l}\text { The total registered capital of new companies in the new } \\
\text { economic industry accounted for the total registered } \\
\text { capital of all newly added companies during the period }\end{array}$ \\
\hline \multirow{3}{*}{$\begin{array}{l}\text { Technological } \\
\text { innovation }\end{array}$} & Researcher ratio & Proportion of scientific researchers during the period \\
\hline & New patents in the new economy & $\begin{array}{l}\text { Proportion of new inventions and utility model patents in } \\
\text { the new economic industry during the period }\end{array}$ \\
\hline & $\begin{array}{l}\text { New economic industry patent } \\
\text { conversion rate }\end{array}$ & $\begin{array}{l}\text { The ratio of the frequency of invention patent circulation } \\
\text { in the new economic industry during the period }\end{array}$ \\
\hline
\end{tabular}

\subsection{Determination of indicator weight}

There are two main methods for determining the weight of new economic indicators: empirical data method and principal component analysis. Comprehensive comparison of the two methods, this paper selects the empirical data method to determine the weight of the new economic index indicator system.

The data shows that the proportion of labor compensation in the tertiary industry in China accounted for $47.2 \%$ of the added value in 2014 . As far as the specific industry is concerned, the labor compensation of the information transmission industry accounted for $23.4 \%$, and the labor compensation of the scientific research industry accounted for The ratio is $49.7 \%$. Since the new economic industry is an industry that "invests with high-quality labor as the main factor", this paper sets the weight of labor input to 40\%, and the capital investment and technological innovation to 35\% and $25 \%$ respectively. At the same time, all secondary indicators are combined into a corresponding primary index by simple arithmetic average. 


\subsection{Synthesis of new economic index}

After the specific classification of the selected enterprises, the share of the new economic industrial units in the process of economic output is calculated. This paper uses the Cobb-Douglas production function to measure the output share of new economic enterprises[4]. The standard form of the Cobb-Douglas production function is:

$$
Q=A L^{\alpha} K^{\beta} e^{\mu}, \alpha+\beta=1
$$

Among them: $Q$ represents the total output, $A$ indicates the technical level (constant), $L$ shows the human capital, $K$ expresses the capital, $\alpha$ is the elasticity coefficient of labor output, $\beta$ is the elasticity coefficient of capital output, and $\mu$ is the influence of random interference terms.

Considering that the output of new economic enterprises is not only affected by capital and human capital, but also by technological innovation, that is, $Q$ will also be affected by the factors of $A$, while technology and labor are the main factors affecting technological innovation, therefore, we introduce a new variable $\mathrm{H}$, and then form an integrated technical level with A. The resulting new production function is:

$$
Q=(A H)^{\omega} L^{\alpha} K^{\beta}, \alpha+\beta+\omega=1
$$

Assuming that each factor has a certain share of the new economic industry, then the share of the new economy in total economic output is:

$$
\frac{Q_{\text {new }}}{Q}=\frac{\left(\theta_{1} A H\right)^{\omega}\left(\theta_{2} L\right)^{\alpha}\left(\theta_{3} K\right)^{\beta}}{(A H)^{\omega} L^{\alpha} K^{\beta}}=\theta_{1}^{\omega} \theta_{2}^{\alpha} \theta_{3}^{\beta}
$$

The logarithm of the equal sign on the equation (3):

$$
\ln \frac{Q_{\text {new }}}{Q}=\omega \ln \theta_{1}+\alpha \ln \theta_{2}+\beta \ln \theta_{3}
$$

The above formula is the share of the new economy in the total output of the economy. In the actual process, the ratio is not only affected by labor capital and technology, but includes more detailed secondary indicators. Therefore, each of the above indicators The weight of the decentralization will also decrease accordingly, then the equation (4) can be approximately equal to:

$$
\frac{Q_{\text {new }}}{Q}=\omega \theta_{1}+\alpha \theta_{2}+\beta \theta_{3}
$$

Also because $\alpha+\beta+\omega=1$, then equation (5) can be simplified to:

$$
\frac{Q_{\text {new }}}{Q}=\sum_{i} \varepsilon_{i} \theta_{i}
$$

It can be seen from the above formula that by investing in the proportion of various factors in the new economic industry, the new economic index can be obtained by weighting the new economic share of each factor according to its output elasticity.

\section{New economic industry development measure}

This paper collects the raw data of enterprises from July to December 2017 through various channels such as the big data published by the network, the Chengdu Statistical Yearbook, the Chengdu Science and Technology Statistical Yearbook and the industry identification method, and roughly calculates the Chengdu New Economic Index. And compared with the national new economic index, it is concluded that the development of Chengdu's new economic industry is ahead of the national average.

From the total number of new economic indicators, the average value of Chengdu's new economic index in the second half of 2017 is 36.9, which means that the proportion of investment in the new economic industry to the national economy is $36.9 \%$, which is 6.4 percentage points higher than the national average. It shows that the development of Chengdu's new economic industry is ahead of the national average and has certain development advantages. In the second half of 2017, Chengdu's monthly new economic index fluctuated little. In December 2017, Chengdu's new economic index reached the highest level of 37.4, which was 6 percentage points higher than the national new 
economic index; In October 2017, Chengdu's new economic index was the lowest, at 36.4, 7.5 percentage points higher than the national new economic index; the highest month is only 1 percentage point lower than the lowest month. From this we can see that in the second half of 2017, the development of Chengdu's new economic industry is more robust. Due to the lack of data from other provinces to measure the new economic index, it is difficult to compare horizontally.

In terms of the contribution of the first-level indicators to the new economic index, for example, the new economic index of Chengdu rose by 0.7 percentage points in December 2017. Among them, labor input fluctuated slightly, with the December index of 33.3, falling 1 percentage point from the previous month; capital input showed an increasing trend, with the December index of 42.3, rising 1.3 from the previous month; scientific and technological innovation grew faster, with the December index of 38.1, rising 1.2 percentage points from the previous month. Considering the weight of the first-level indicator, the contribution of labor to the change of NEI in December is -0.1 , the contribution of capital investment to the change of NEI in December is 0.5, and the contribution of technological innovation to the change of NEI in December is 0.3 , a total of 0.7 percentage points. Capital investment has the greatest contribution.

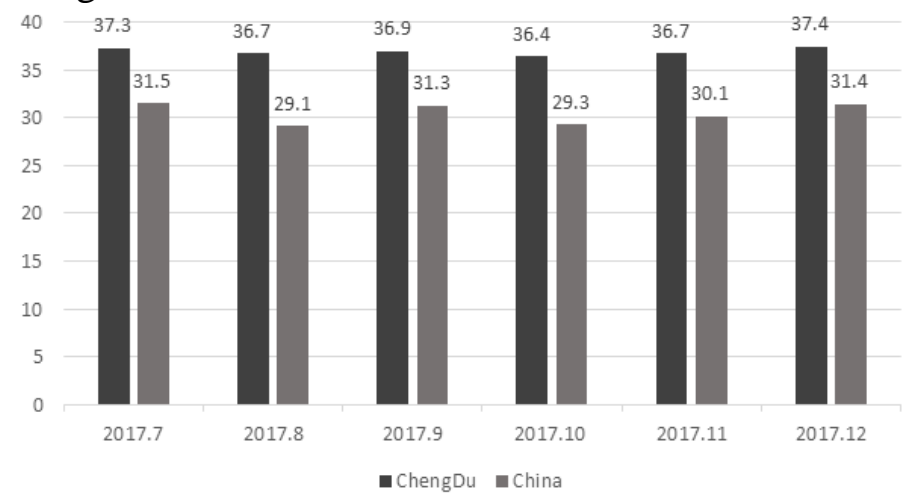

Fig. 1. Chengdu and the National New Economic Index from July to December 2017

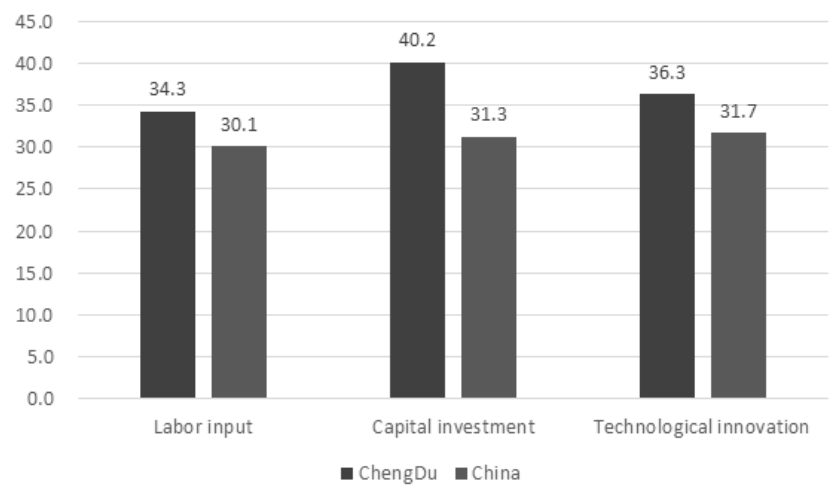

Fig. 2. Investment in Chengdu and the country's new economic factors from July to December 2017

From the perspective of factor structure, Chengdu's investment in the three major new economic and industrial factors of labor input, capital investment and technological innovation is higher than the national average. Among them, the labor input is 4.2 percentage points higher than the national average, the capital investment is 8.9 percentage points higher than the national level, and the scientific and technological innovation is 4.6 percentage points higher than the national level. This shows that Chengdu's new economic industry development foundation, especially the core elements, has strong supporting capacity. The capital investment for developing new economic industries is relatively strong, more investment in talent, and endogenous development momentum is stronger.

On the whole, the development level of Chengdu's new economic industry is relatively advanced, that is, it is higher than the development level of new economic industries in most cities, which is related to Chengdu's own diversified development. However, the development of Chengdu's new economic industry is not at the leading level in the country. It still has a certain gap with the coastal developed areas such as Beijing, Shanghai, Guangzhou and Shenzhen. If Chengdu wants to achieve 
catch-up, it must further support the development of leading industries in line with Chengdu's reality and lead industrial development, and formulate relevant industrial policies to support the sound and rapid development of new economic industries.

\section{Conclusion}

Since the 21st century, artificial intelligence, big data, cloud computing, and the Internet of Things have spawned a series of new industries, new formats, and new models, which have promoted the transformation of global industries. It has provided a strong impetus for the development of the new normal of China's economy. As a leading city for the development of the inland new economy, Chengdu has achieved certain results in the development of new economic industries, but it still has great shortcomings. Based on the reality of Chengdu's new economic development, this study considers the individualization of Chengdu's new economic development and the availability of new economic indicators, classifies the structure of production factors, and establishes a set of measures for the development of new economic development in Chengdu. On the basis of this, the Cobb-Douglas production function is used to calculate the Chengdu New Economic Index, which will form a new economic industrial system with global competitiveness and regional driving force in Chengdu in 2022, and become the discourse leader of the new economy. , the elemental gathering place and the ecological innovation zone, and the establishment of a new type of city that is most suitable for the development of new economy provides decision-making assistance.

\section{Acknowledgements}

This research was financially supported by the Chengdu Soft Science Research Key Project (Grant NO. 2017-RK00-00097-ZF).

\section{References}

[1] Weitao Chen, The Core Connotation of "New Economy" and Its Statistical Measurement, Nanjing Journal of Social Sciences, vol.11, pp. 23-30, 2017.

[2] Meihui Zhang, Progress in International New Economic Measurement Research and Its Reference to China, Economist, vol.11, pp. 47-55, 2017.

[3] Xi Chen, Zhonghua Wang, Accelerate the Construction of China's New Economy Monitoring and Evaluation Index System-The Enlightenment of American New Economic Index to China, Price:Theory \& Practice, vol.3, pp. 112-115, 2017.

[4] Xiaohua Dong, Xin Wang, Li Chen, A Summary of Cobb Douglas Production Function Theory Research, Productivity Research, vol.3, pp. 148-150, 2008. 